\title{
Small Square Reconfigurable Antenna with Switchable Single/Tri-Band Functions
}

\author{
Mehri BORHANI KAKHKI, Pejman REZAEI, Vahid SHARBATI, Mohammad M. FAKHARIAN \\ Dept. of Electrical and Computer Engineering, Semnan University, Semnan, Iran \\ borhani.mehri@semnan.ac.ir, prezaei@semnan.ac.ir, v.sharbati@semnan.ac.ir,m_fakharian@semnan.ac.ir \\ Manuscript received June 18, 2015
}

\begin{abstract}
A novel frequency reconfigurable slot antenna for suitable switchable radiations at WLAN and a tri-band at Bluetooth, WiMAX and upper WLAN applications is designed and fabricated. Switchable frequency responses are achieved by implementation of a PIN diode within the antenna ground plane. The antenna structure consists of a square radiation patch with an E-shaped slot, a modified ground plane with an inverted T-shaped strip that acts as a parasitic stub and two parallel slots and a protruded strip which is connected to the parasitic stub with a PIN diode. The presented antenna has a compact size of $20 \times 20 \mathrm{~mm}^{2}$ while providing switchable radiations at 2.36-2.5 GHz Bluetooth, 3.51-3.79 GHz WiMAX, and 5.47-5.98 GHz WLAN when the diode is ON and 5.04-6.13 GHz WLAN when the diode is OFF.
\end{abstract}

\section{Keywords}

E-shaped slot, frequency reconfigurable, inverted Tshaped strip, parasitic stub, rectangular-shaped notches

\section{Introduction}

Newly, with the development of novel communication systems, frequency reconfigurable antennas have gained a lot of attention, by adapting their properties to achieve selectivity in frequency, polarization, bandwidth, and gain [1], [2]. In order to create frequency reconfigurable antennas, external parameters, typically a DC voltage is implemented through embedding a variable element to the antenna structure such as PIN diodes [3], [4] or varactor diodes [5]. It is a well-known fact that these antennas present appealing features, such as effortless design and manufacture, compact size, simple structure, using multiple frequency bands and more economical. Reconfigurable antennas are extremely attractive to be used in integrated circuits applications [6-9]. In order to create multiband antennas, several techniques such as cutting slots on the metal parts of the antenna or using multiple radiating sections has been proposed recently [10-12]. Using slots or multiple radiating parts to create additional resonance usually causes inevitable degradation of the input matching and the radiation pattern at other resonance frequencies especially when they are introduced unsymmetrically to the antenna structure [5].

In this paper, the design, simulation and measurement of a compact microstrip slot antenna is demonstrated. One RF PIN diode on the ground plane of the antenna is used to form a frequency reconfigurable structure. By changing state of this diode between OFF and ON modes, the proposed antenna is able to switch between the WLAN and a tri-band at Bluetooth, WiMAX and upper WLAN systems respectively.

\section{Antenna Design and Configuration}

Figure 1 shows the proposed square antenna structure with its design parameters. It is designed on both sides of a FR4 substrate with $0.8 \mathrm{~mm}$ thickness, relative permittivity 4.4 and loss tangent 0.018 . In the presented structure, an E-shaped slot is embedded on the square radiating patch which is fed by a modified feedline. Two symmetrical rectangular-shaped notches have been added to the feedline to further enhance the matching. Also the ground plane included two parts. One part is an inverted T-shaped strip that acts as a parasitic stub. The other part consists of two parallel slots that act as DGS to current disturbance on the back of the feedline and a protruded rectangular strip. The inverted T-shaped strip is connected to the protruded rectangular strip by means of a PIN diode. The final values of the design parameters are listed in Tab. 1. The antenna was simulated by the aid of the Ansoft simulation software High Frequency Structure Simulator (HFSS) [13].

Figure 2 shows the various antenna structures used for simulation studies and their return loss characteristics are compared in Fig. 3.

As illustrated in Fig. 3, there are six steps in designing of this study which have been stated as below: First of all, we started by the design of an ordinary antenna which consists of a rectangular-shaped slot on the ground plane. This rectangular-shaped slot causes a resonance at frequen- 


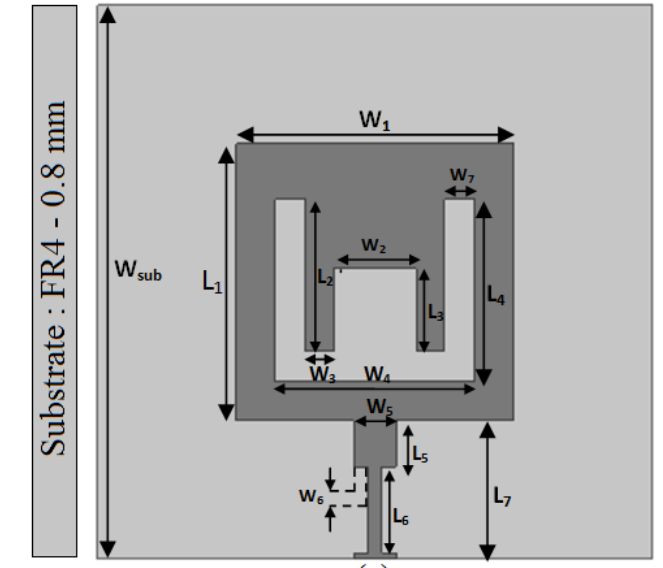

(a)

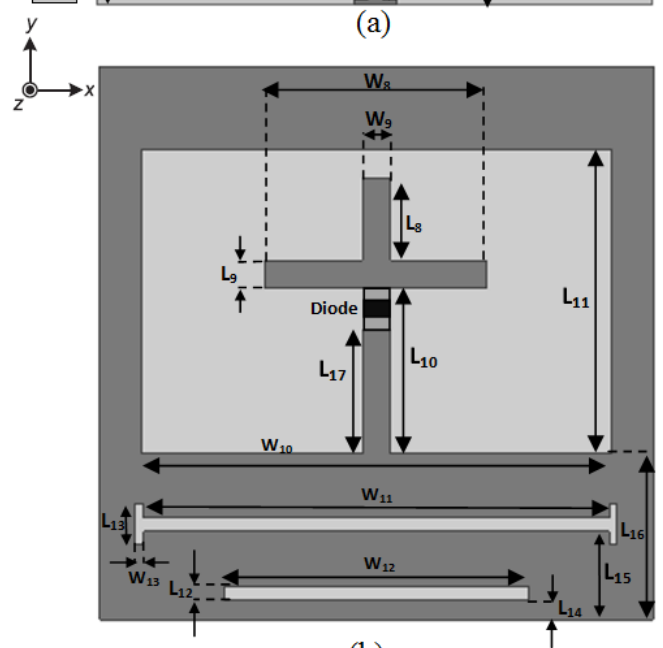

(b)

Fig. 1. The geometry of the proposed antenna structure: (a) Top layer. (b) Bottom layer.

\begin{tabular}{|c|c|c|c|c|c|c|c|}
\hline Param. & mm & Param. & mm & Param. & mm & Param. & mm \\
\hline Wsub & 20 & W8 & 8 & L3 & 3 & L11 & 11 \\
\hline W1 & 10 & W9 & 1 & L4 & 6.6 & L12 & 0.5 \\
\hline W2 & 3 & W10 & 17 & L5 & 1.7 & L13 & 1.5 \\
\hline W3 & 1 & W11 & 16.8 & L6 & 3.1 & L14 & 0.7 \\
\hline W4 & 7.2 & W12 & 11 & L7 & 5 & L15 & 3.2 \\
\hline W5 & 1.5 & W13 & 0.3 & L8 & 3 & L16 & 6 \\
\hline W6 & 0.5 & L1 & 10 & L9 & 1 & L17 & 4.5 \\
\hline W7 & 1.1 & L2 & 5.5 & L10 & 6 & & \\
\hline
\end{tabular}

Tab. 1. Dimensions of the designed antenna.

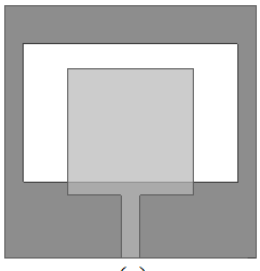

(a)

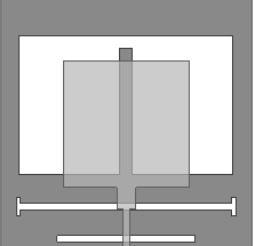

(d)

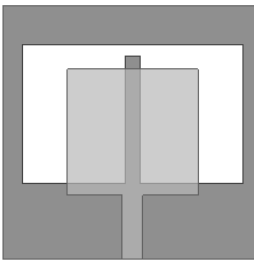

(b)

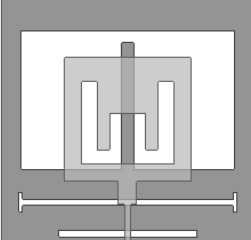

(e)

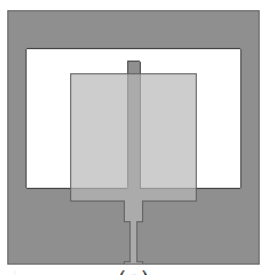

(c)

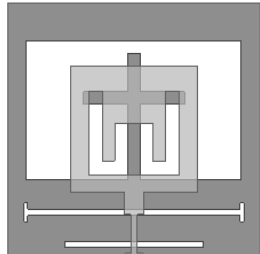

(f)
Fig. 2. Different simulated antenna structures.

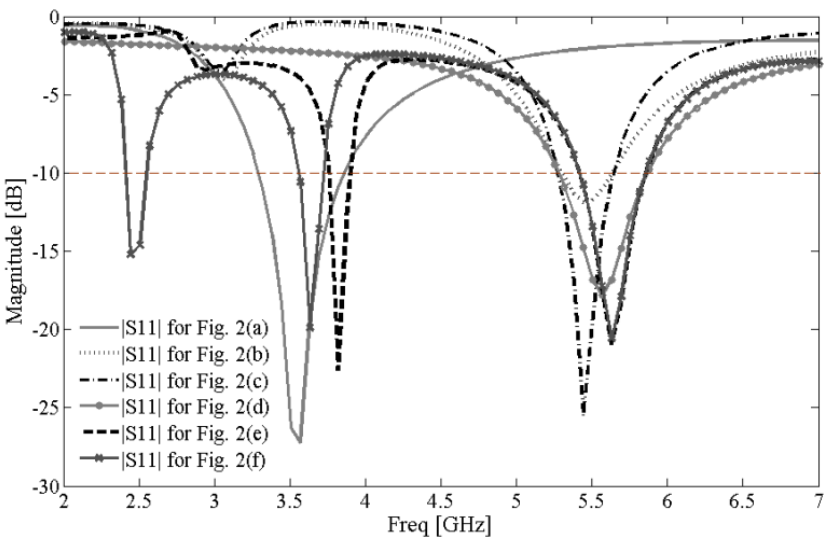

Fig. 3. The frequency responses of various antenna structures shown in Fig. 2.

cies near $3.5 \mathrm{GHz}$ (Fig. 2(a)). In order to move the resonance frequency toward higher frequencies, a protruded rectangular strip have been added to ground plane and the antenna is able to cover frequencies near $5.5 \mathrm{GHz}$, as shown in Fig. 2(b). The feedline is etched symmetrically to further enhance the matching (Fig. 2(c)). In order to achieve impedance bandwidth enhancement, two parallel slots are etched on the ground plane under the feedline which leads to disturbance of the current distribution on the ground plane. Their distance from each other and their dimensions play an important role in order to obtain the desired result, whereas the absence of each eliminates the resulting resonance frequency (Fig. 2(d)). By embedding an E-shaped slot on the square radiating patch, a dual band at frequencies near $3.8 \mathrm{GHz}$ and $5.6 \mathrm{GHz}$ is achieved (Fig. 2(e)). Finally by transforms of a rectangle element to an inverted cross-shaped sleeve at the ground plane and forming the antenna structure in Fig. 2(f), the antenna is able to exhibit a tri-band at Bluetooth, WiMAX and upper WLAN systems at frequencies near $2.45 \mathrm{GHz}, 3.63 \mathrm{GHz}$ and $5.64 \mathrm{GHz}$, respectively.

For narrow strips, i.e. $w / h<3.3$, with the knowledge of $w / h$ and $\varepsilon_{\mathrm{r}}, Z_{\mathrm{o}}$ is calculated [14].

$$
\begin{aligned}
Z_{\mathrm{o}}= & \frac{119.9}{\sqrt{2\left(\varepsilon_{\mathrm{r}}+1\right)}}\left\{\ln \left[\frac{4 h}{W}+\sqrt{16\left(\frac{h}{W}\right)^{2}+2}\right]\right. \\
& \left.-\frac{1}{2}\left(\frac{\varepsilon_{\mathrm{r}}-1}{\varepsilon_{\mathrm{r}}+1}\right)\left(\ln \frac{\pi}{2}+\frac{1}{\varepsilon_{\mathrm{r}}} \ln \frac{4}{\pi}\right)\right\}
\end{aligned}
$$

where $w$ is the width of the feedline, $h$ is the thickness of the substrate and $\varepsilon_{\mathrm{r}}$ is the dielectric constant. According to (1), the calculated characteristic impedance $Z_{\mathrm{o}}$ of the feedline is $50.59 \Omega$.

\subsection{Parametric Study}

Numerical parametric studies have been done to optimize the designs and to obtain the final values.

The simulated return loss curves with different values of the $L_{8}$ parameter are plotted in Fig. 4 . So, when $L_{8}$ increases from 1 to $3 \mathrm{~mm}$, the center frequency decreases 
from $2.6 \mathrm{GHz}$ to $2.42 \mathrm{GHz}$. In Fig. 5(a) and (b), alternation of $W_{12}$ in the presence and the absence of the diode respectively has been shown as a key parameter in adjusting the WLAN resonance. Also by altering the design parameter $L_{10}$ from 6 to $7 \mathrm{~mm}$ by step of $0.5 \mathrm{~mm}$ in the absence of the diode, the bandwidth can be adjusted at WLAN, as shown in Fig. 6. Figure 7 shows how the length of the $L_{17}$ effects and determines the appropriate location for the PIN diode.

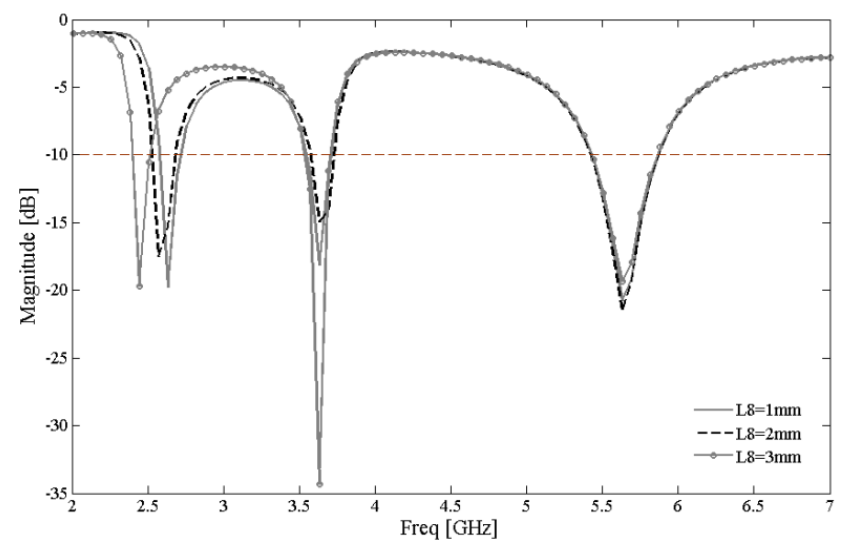

Fig. 4. Simulated return loss characteristic with different values of $L_{8}$.

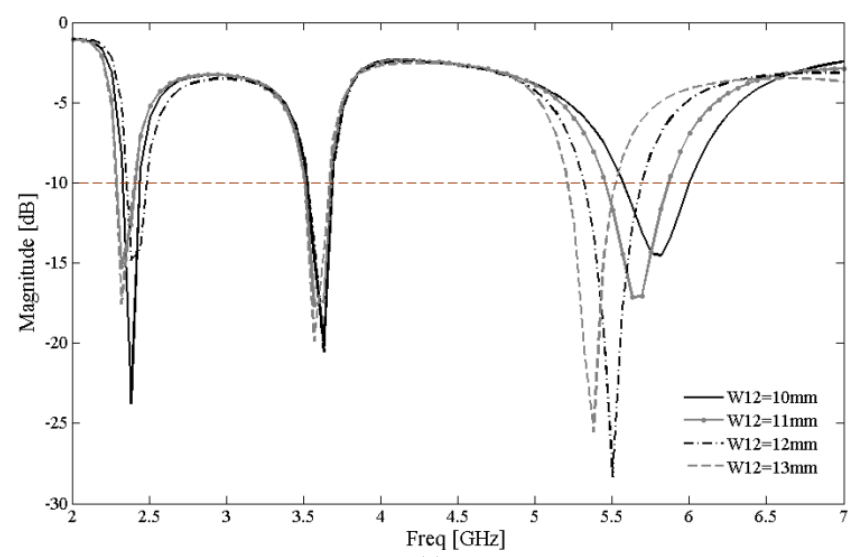

(a)

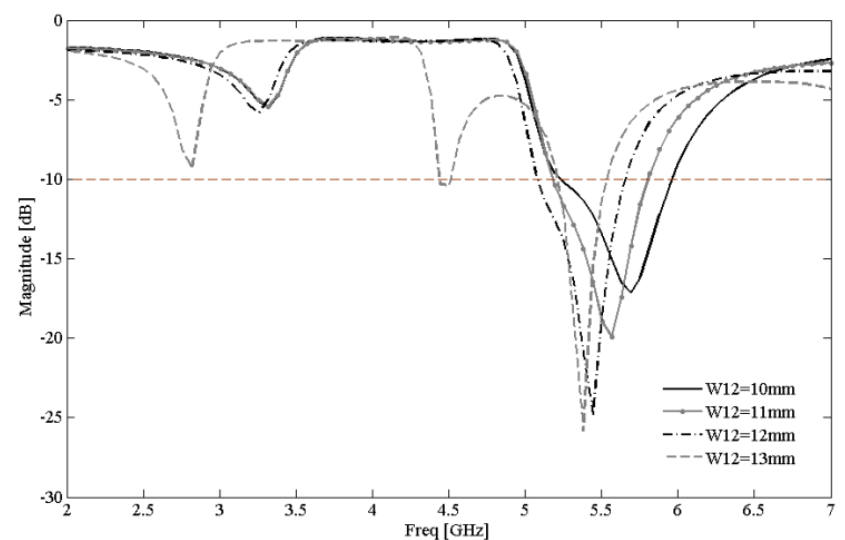

(b)

Fig. 5. Simulated return-loss characteristics of the proposed antenna with different values of $W_{12}$ in (a) the presence and (b) the absence of the diode.

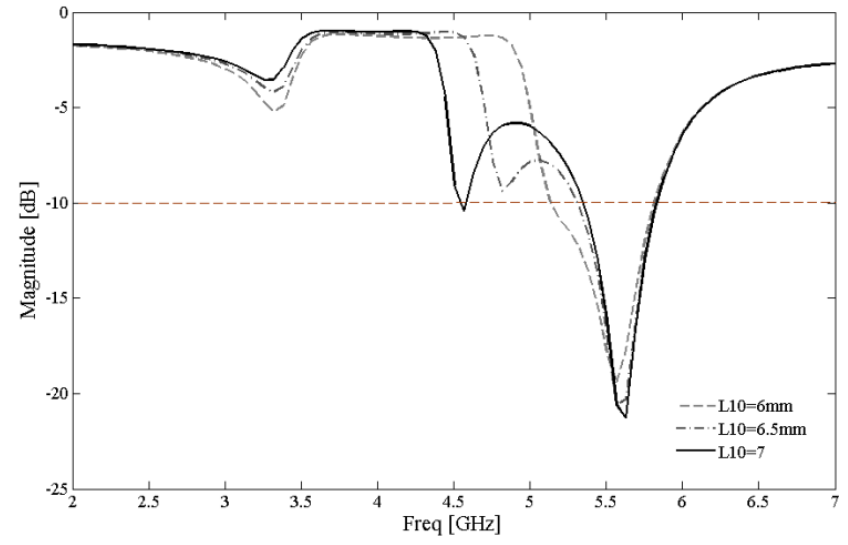

Fig. 6. Simulated return loss characteristic in absence of the diode with different values of $L_{10}$.

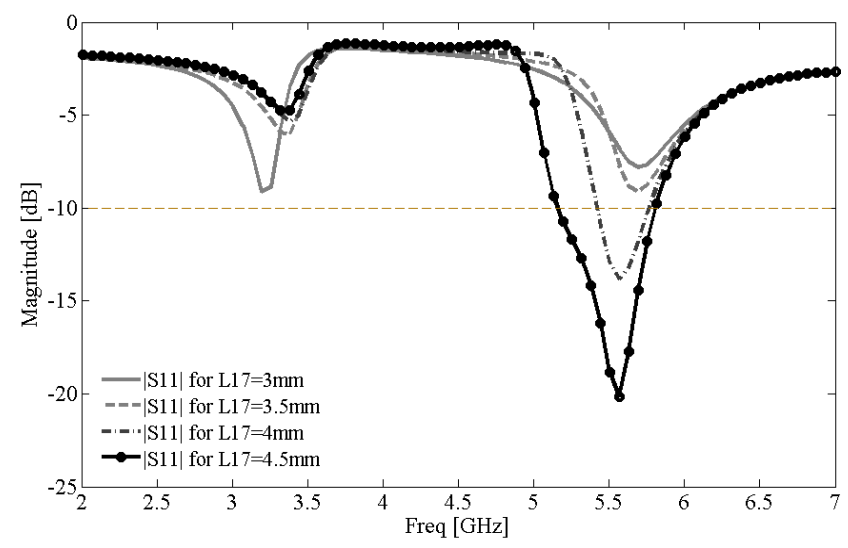

Fig. 7. Simulated return loss characteristic in absence of the diode with different values of $L_{17}$.

\section{Results and Antenna Performance}

In this section, the proposed antenna with its final optimized parameters is designed, fabricated and tested and the numerical and experimental results of its return loss and radiation characteristics are presented and discussed. Figure 8 shows the photograph of a manufactured prototype.

There are two techniques to imitate PIN diode switch in the simulation. In the first technique, ideal switch models are used. This means that the closed (ON) and opened (OFF) states of the switch are simulated in the presence or absence of a metal pad, respectively. In the second technique, PIN diode was modeled as a capacitance/resistor in the $\mathrm{OFF} / \mathrm{ON}$ state, respectively; the second technique is used in this design. According to the datasheet of the BAR64 [15], PIN diode is simulated as a $2.1 \Omega$ resistor and $0.17 \mathrm{pF}$ capacitor in the ON and OFF states, respectively. Accordingly, simulated and measured return loss characteristic of designs for various bias conditions of the PIN diode are shown in Fig. 9. According to Fig. 9, it is possible to switch the frequency in two states. When the diode is $\mathrm{OFF}$, the antenna only covers the frequency WLAN range 


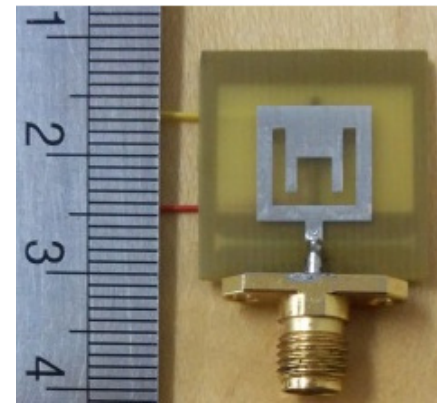

(a)

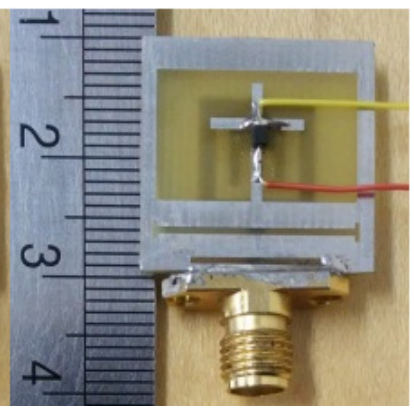

(b)
Fig. 8. The photograph of the fabricated reconfigurable slot antenna with DC biased: (a) top view, (b) back view.

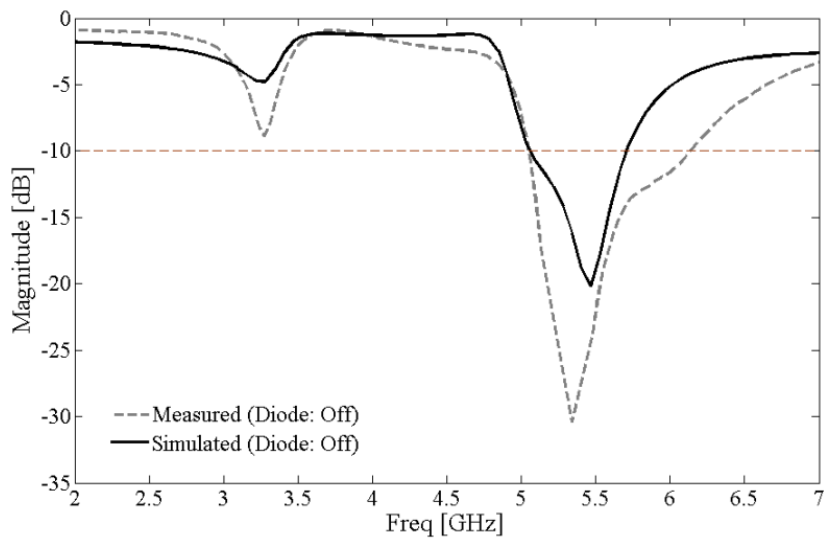

(a)

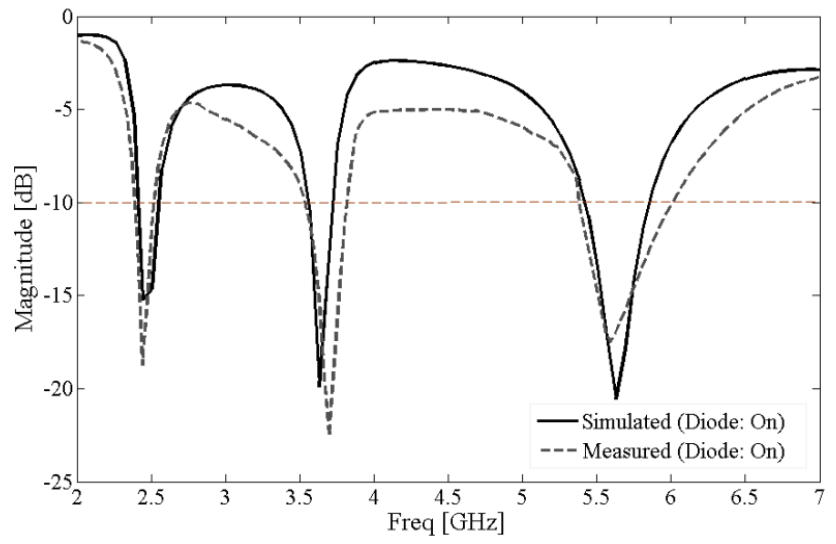

(b)

Fig. 9. Measured and simulated return-loss results in the proposed antenna. (a) Diode is OFF. (b) Diode is ON.

of $(5.04-6.13 \mathrm{GHz})$. When the diode is $\mathrm{ON}$, it is observed that antenna covers the frequency range of $(2.36-2.5 \mathrm{GHz})$, $(3.51-3.79 \mathrm{GHz})$ and $(5.47-5.98 \mathrm{GHz})$ which are Bluetooth, a part of the WiMAX and WLAN applications respectively. Good agreement between the measured results and simulation predictions is achieved; however, there exist some discrepancies which can be due to some reasons such as fabrication tolerance, the implementation of the PIN diode and their biasing circuits and the effects of the SMA connector [3].

Moreover in order to demonstrate the phenomenon behind the performance of the presented antenna, Fig. 10(a) to (d) depicts the simulated vector surface cur-

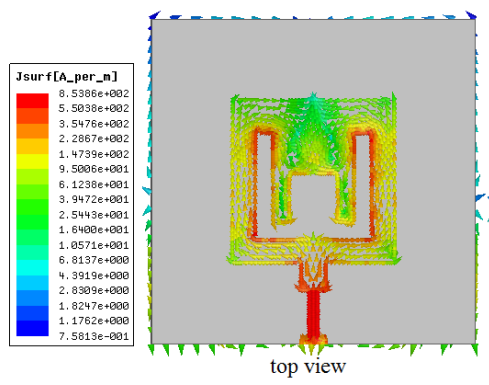

(a)
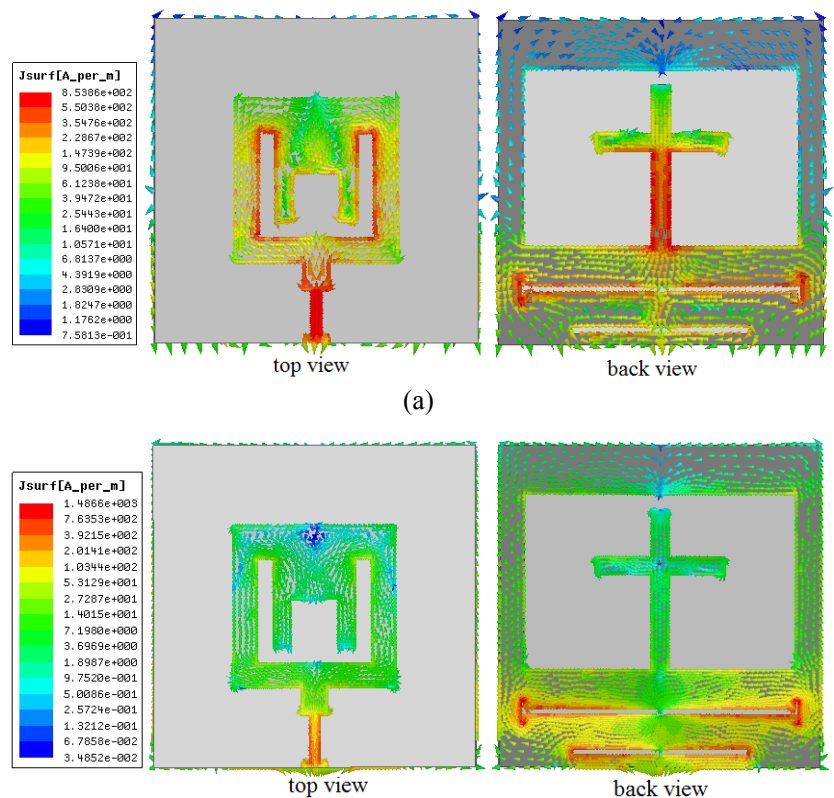

(b)

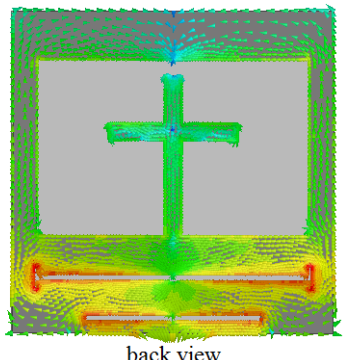

back view

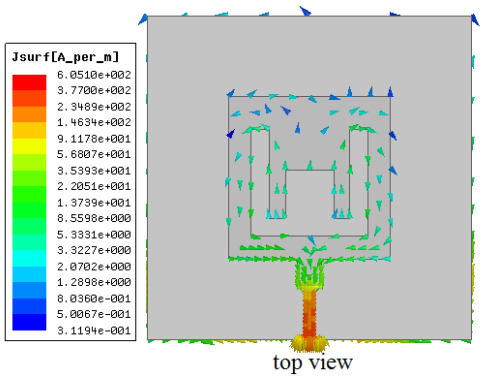

(c)

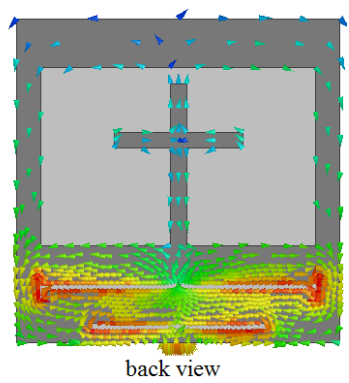

back view

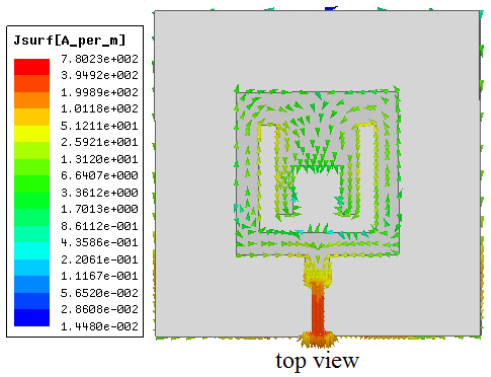

(d)

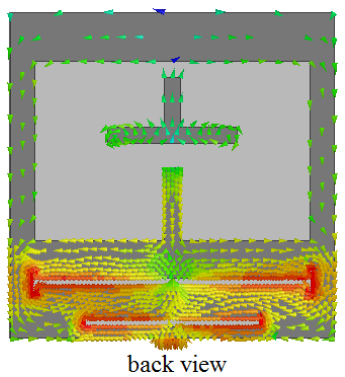

back view

Fig. 10. Simulated current distributions of the antenna in both states when: switch is in ON-state at (a) $2.5 \mathrm{GHz}$, (b) $3.5 \mathrm{GHz}$, (c) $5.3 \mathrm{GHz}$, (d) switch is OFF-state at $5.5 \mathrm{GHz}$.

rent distribution for OFF and $\mathrm{ON}$ states of the diode. From this figure, it can be seen that for different resonance frequencies, the antenna structure has a corresponding resonating path.

The gains of switchable Single/Tri-Band antennas are measured independently using gain comparison method and shown in Fig. 11. In this figure, the gain is measured in both the planes of the radiation pattern and the peak gain is selected from either plane which gives the larger value. The antennas have moderate gain with variations $<5 \mathrm{dBi}$ throughout the operating band, while the gain drops up to $-7 \mathrm{dBi}$ in the other frequencies. The efficiency of the antenna for both ports is measured using the wheeler cap 


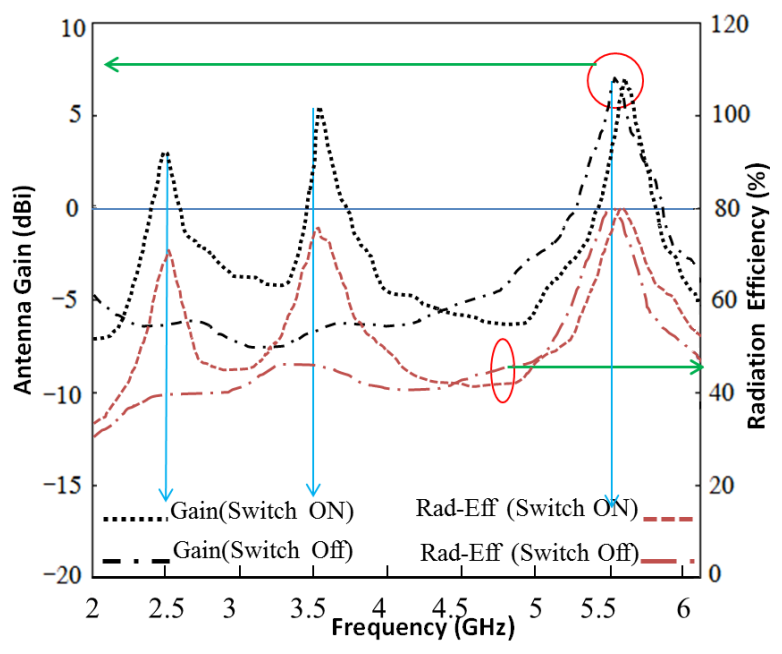

Fig. 11. Measured peak gain and radiation efficiency of the proposed antenna.

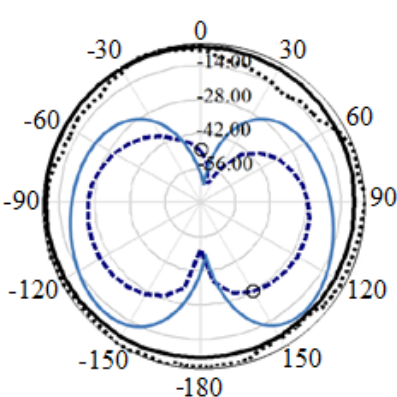

H-Plane $2.5 \mathrm{GHz}$

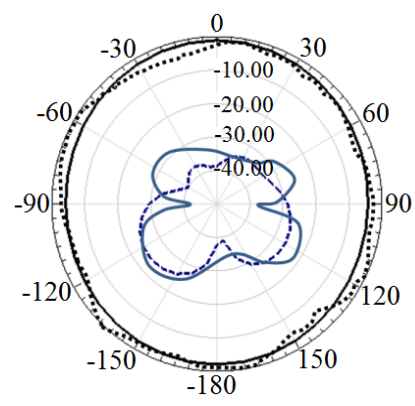

H-Plane $3.6 \mathrm{GHz}$

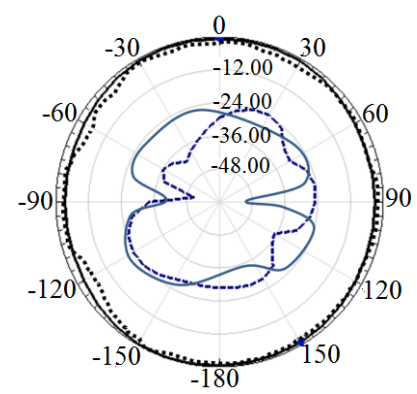

H-Plane $5.3 \mathrm{GHz}$

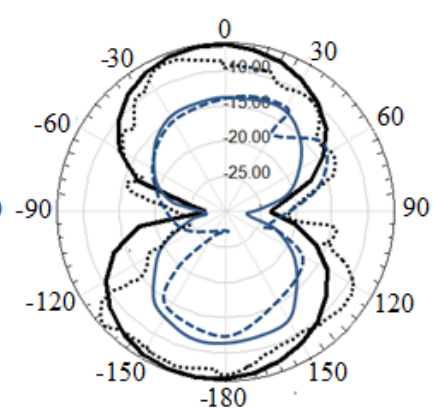

E-Plane $2.5 \mathrm{GHz}$

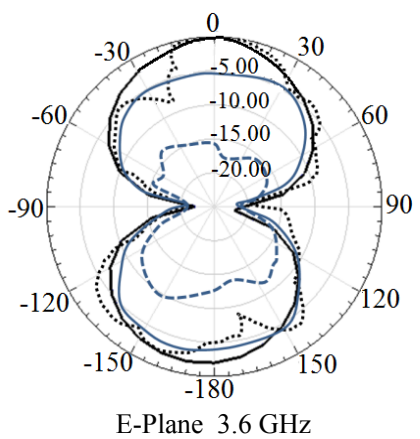

E-Plane $3.6 \mathrm{GHz}$

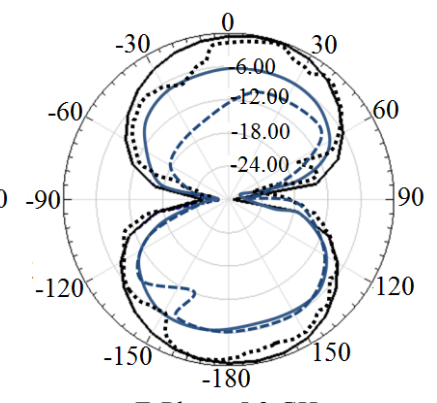

E-Plane $5.3 \mathrm{GHz}$

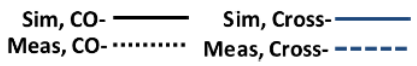

Fig. 12. Simulated and measured normalized radiation patterns of the antenna in the E- and H-planes when the diode is $\mathrm{ON}$.

method and is also incorporated in Fig. 11. The antenna provides efficiency better than $70 \%$ in the bands of 2.5 GHz, 3.6 GHz and $5.3 \mathrm{GHz}$ when the diode is ON state and when the diode is OFF state at $5.5 \mathrm{GHz}$ while it drops to $40 \%$ in the other band.

The measured and simulated normalized radiation patterns in the E- and H-planes for the antenna at $2.5 \mathrm{GHz}$, $3.6 \mathrm{GHz}$ and $5.3 \mathrm{GHz}$, when the diode is $\mathrm{ON}$, are shown in Fig. 12(a), (b) and (c), respectively. As seen from these figures, the measured and simulated radiation patterns reasonably agree well. As can be seen in Fig. 12, the radiation patterns of this antenna are nearly omnidirectional for the three frequencies in H-plane which is desired for most related applications and E-plane patterns depict a dipolelike pattern for $2.5 \mathrm{GHz}, 3.6 \mathrm{GHz}$ and $5.3 \mathrm{GHz}$ [4]. The radiation pattern for the OFF state of the diode at $5.5 \mathrm{GHz}$ is also examined and compared with the simulated results, whereas it is almost the same as the radiation pattern in the ON state at $5.3 \mathrm{GHz}$, it is not shown for brevity.

\section{Conclusion}

In this paper, a novel compact slot antenna with two switchable states has been proposed for frequency agility between WLAN at (5.04-6.13 GHz) and a tri-band consisting of Bluetooth at $(2.36-2.5 \mathrm{GHz})$ and a part of the WiMAX at (3.51-3.79 GHz) and upper WLAN at (5.47 to $5.98 \mathrm{GHz}$ ) applications with desired omnidirectional radiation patterns at H-plane. The frequency is controlled by only one PIN diode, which is connecting an inverted Tshaped strip to a protruded strip in the ground plane. The antenna has the merits of simple and low cost structure. The experimental measurements were in good correlation with the simulation results showing that the proposed antenna can be a good candidate for modern cognitive multiband systems.

\section{Acknowledgment}

This study was supported by Semnan University. The authors would like to thank the ITRC Antenna Lab members, especially Mr. Solat, Mr. Mirabdollahi and Mr. Akhlaghpasandi, for their cooperation. Also, the authors would like to thank the anonymous reviewers for their constructive comments.

\section{References}

[1] PAZIN, L., LEVIATAN, Y. Reconfigurable slot antenna for switchable multiband operation in a wide frequency range. IEEE Antennas and Wireless Propagation Letters, 2013, vol. 12, p. 329-332. DOI: 10.1109/LAWP.2013.2246855

[2] FAKHARIAN, M. M., REZAEI, P., OROUJI, A. A. Reconfigurable multiband extended U-slot antenna with 
switchable polarization for wireless applications. IEEE Antennas and Propagation Magazine, 2015, vol. 57, no. 2, p. 194-202, DOI: 10.1109/MAP.2015.2414665

[3] VALIZADE, A., OJAROUDI, M., OJAROUDI, N. CPW-fed small slot antenna with reconfigurable circular polarization and impedance bandwidth characteristics for DCS/WIMAX applications. Progress in Electromagnetics Research C, 2015, vol. 56, p. 65-72. DOI: 10.2528/PIERC14122901

[4] VAlizAde, A., ReZAeI, P., OROUJI, A. A. Design of reconfigurable active integrated microstrip antenna with switchable low-noise amplifier/power amplifier performances for wireless local area network and WiMAX applications. IET Microwaves, Antennas and Propagation, 2015, vol. 9, no. 9, p. 872-881. DOI: 10.1049/iet-map.2014.0704

[5] KEHN, M. N. M., QUEVEDO-TERUEL, O., RAJO-IGLESIAS, E. Reconfigurable loaded planar inverted-F antenna using varactor diodes. IEEE Antennas and Wireless Propagation Letters, 2011, vol. 10, p. 466-468. DOI: 10.1109/LAWP.2011.2153174

[6] OJAROUDI, M., GHOBADI, Ch., NOURINIA, J. Small square monopole antenna with inverted T-shaped notch in the ground plane for UWB application. IEEE Antennas and Wireless Propagation Letters, 2009, vol. 8, p. 728-731. DOI: 10.1109/LAWP.2009.2025972

[7] FAKHARIAN, M. M., REZAEI, P., OROUJI, A. A. A novel slot antenna with reconfigurable meander-slot DGS for cognitive radio applications. Applied Computational Electromagnetics Society Journal, 2015, vol. 30, no. 7, p. 748-753.

[8] SHARBATI, V., REZAEI, P., SHAHZADI, A., et al. A planar UWB antenna based on MB-OFDM applications with switchable dual band-notched for cognitive radio systems. International Journal of Microwave and Wireless Technologies, October 2014 (published online), p. 1-8. DOI: 10.1017/S1759078714001317

[9] SHARBATI, V., REZAEI, P., FAKHARIAN, M. M., et al. A switchable band-notched UWB antenna for cognitive radio applications. IETE Journal of Research, vol. 61, no. 4, p. 423-428. DOI: $10.1080 / 03772063.2015 .1025108$

[10] BADAMCHI, B., VALIZADE, A., REZAEI, P., et al. A reconfigurable square slot antenna with switchable single band, UWB and UWB with band notch function performances. Applied Computational Electromagnetics Society Journal, 2014, vol. 29, no. 5, p. 383-390. ISSN: 1054-4887

[11] BADAMCHI, B., NOURINIA, J., GHOBADI, Ch., et al. A design of compact reconfigurable UWB slot antenna with switchable single/dual band notch functions. IET Microwaves, Antennas and Propagation, 2014 , vol. 8 , no. 8, p. $541-548$. DOI: $10.1049 /$ ietmap.2013.0311

[12] FAKHARIAN, M. M., REZAEI, P., OROUJI, A. A. Microstrip antenna with a reconfigurable Dumbbell-shaped defected ground plane for DCS-1800 and PCS-1900. In IEEE International Symposium of Antennas and Propagation Society (APSURSI). Orlando (FL, USA), 2013, p. 576-577. DOI: 10.1109/APS.2013.6710948

[13] Ansoft High Frequency Structure Simulator (HFSS), Ver. 13, Ansoft Corporation, 2010.
[14] YIP, P. High-Frequency Circuit Design and Measurements. $1^{\text {st }} \mathrm{ed}$. 1990. ISBN: 0-412-34160-3

[15] Infineon Technologies, BAR64 Silicon PIN Diode, (datasheet). 16 pages. [Online] Cited 2006-02-01. Available at: http://www.alldatasheet.com/datasheetpdf/pdf/396636/INFINEON /BAR64-06.html

\section{About the Authors ...}

Mehri BORHANI KAKHKI was born in Gonabad, Iran, in 1989. She received her B.S. degree in Communication Engineering from the Electrical and Computer Engineering Faculty, University of Sistan and Baluchesten, Zahedan, Iran, in 2013. Currently, she is working towards the M.S. degree in Communication Engineering from the University of Semnan, Semnan, Iran. Her research interests include reconfigurable microstrip antennas.

Pejman REZAEI was born in Tehran, Iran, in 1977. He received the B.S. degree in Communication Engineering from the Communication Faculty, Tehran, Iran, in 2000, and the M.S. and Ph.D. degrees from Tarbiat Modarres University, Tehran, Iran, in 2002 and 2007, respectively. His current research interests are electromagnetics theory, antennas, wave propagation, and satellite communication. Currently, he is an assistant professor in Semnan University, Semnan, Iran.

Vahid SHARBATI was born in Gorgan, Iran, in 1986. He received his B.S. degree in Electronic Engineering from Hadaf Institute of Higher Education, Sari, Iran, in 2009, and the M.S. degrees in Communication Engineering from Semnan University, Semnan, Iran, in 2015. His current research interest is reconfigurable microstrip antennas for cognitive radio applications.

Mohammad M. FAKHARIAN was born in Tehran, Iran, in 1987. He received the B.S. and M. S. degrees in Electrical Engineering from Semnan University, Semnan, Iran, in 2009 and 2012, respectively. Currently, he is working towards the Ph.D. degree in Communication Engineering from the Semnan University. His research interests include low-profile printed and patch antennas for wireless communication, multiband antennas, EBG structures interaction with antennas and RF passive components, reconfigurable antennas, and electromagnetic theory: numerical methods and optimization techniques. 